\title{
Qualidade do leite bovino nas diferentes estações do ano no estado do Rio Grande do Norte*
}

\section{Quality of milk in different seasons in the Rio Grande do Norte State}

\author{
Kivya Dias de Andrade, ${ }^{* *}$ Adriano Henrique do Nascimento Rangel, ${ }^{* *}$ Viviane Maia de Araújo, ${ }^{* * *}$ \\ Henrique Rocha de Medeiros, ${ }^{* *}$ Karla Cavalcanti Bezerra, ${ }^{* *}$ Rayssa Freire Bezerril,, ${ }^{* *}$ Dorgival Morais de Lima Júnior ${ }^{* \star * *}$
}

\begin{abstract}
Resumo
Objetivou-se com este trabalho avaliar indicadores da qualidade do leite cru de tanques de expansão em dois períodos do ano (seco e chuvoso) na região agreste do estado do Rio Grande do Norte. Para isso, foram coletadas amostras de leite cru diretamente do tanque de expansão de oito propriedades no período de janeiro de 2010 a março de 2012. Os índices mensais médios de precipitação foram coletados do banco de dados da Empresa de Pesquisa Agropecuária do Rio Grande do Norte. As amostras foram analisadas quanto à composição, contagem de células somáticas (CCS) e contagem bacteriana total (CBT). A composição do leite não foi influenciada pela estação do ano $(P>0,05)$ e apresentou médias de 3,53\% para gordura, 3,30\% para proteína e $12,19 \%$ para estrato seco total. Apesar do aumento na precipitação $(P<0,05)$, não houve influencia da estação do ano $(P>0,05)$ sobre os valores de CCS e CBT do leite nos tanques de expansão. A contagem bacteriana total variou de 795 a $505 \mathrm{mil}$ UFC/mL de leite para o período seco e chuvoso, respectivamente. A estação do ano não influenciou na composição, CCS e CBT do leite bovino armazenado em tanques de expansão no agreste do Rio Grande do Norte.
\end{abstract}

Palavras-chave: composição do leite, contagem bacteriana total, estação do ano

\begin{abstract}
The objective of this study was to evaluate indicators of the quality of raw milk from bulk tanks in two seasons (dry and rainy ) in the wild in the state of Rio Grande do Norte. For this, we collected samples of raw milk directly from the expansion tank eight properties in the period January 2010 to March 2012. The average monthly rainfall indices were collected from the database of the Agricultural Research Company of Rio Grande do Norte. The samples were analyzed for composition, somatic cell count (SCC) and total bacterial count (TBC). Milk composition was not affected by season ( $P>0.05)$ and showed an average of $3.53 \%$ for fat, protein and $3.30 \%$ to $12.19 \%$ for total dry stratum. Despite the increased precipitation $(P<0.05)$, there was no influence of season $(P>0.05)$ on the values of the milk SCC and TBC in the expansion tank. The total bacterial count ranged 795-505 mil CFU / ml of milk to the dry and rainy seasons, respectively. The season does not influence the composition, SCC and TBC bovine milk stored in bulk tanks in rural Rio Grande do Norte
\end{abstract}

Keywords: milk composition, total bacterial count, season.

\section{Introdução}

O segmento de produção de leite é um dos mais importantes do Brasil, devido a sua importância sócio econômica. Apesar de gerar divisas, a qualidade da matéria-prima ainda é um grande entrave ao desenvolvimento tecnológico dos laticínios (Borges, 2009).

O conhecimento da composição do leite é essencial para a determinação de sua qualidade, pois define diversas propriedades sensoriais e industriais. Os parâmetros de qualidade são cada vez mais utilizados para detecção de falhas nas práticas de manejo, servindo como referência na valorização da matéria-prima (Dürr, 2004). Segundo Fonseca (2012) os parâmetros relacionados com a qualidade higiênica são muito variados e incluem métodos como a Contagem Bacteriana Total (CBT) e Contagem de Células Somáticas (CCS).
É importante que os parâmetros de qualidade do leite estejam associados à qualidade microbiológica do leite, uma vez que se observa que a maioria dos países reconhecidos pela organização em seu setor lácteo, apresentam os teores de gordura, proteína e demais componentes bem como de CCS e CBT dentro dos padrões da legislação e para efeito do pagamento do leite. Isso se reflete claramente no estudo feito pela IDF (International Dairy Federation), no qual todos os 22 países estudados adotam a CBT para remuneração do produtor (Fonseca, 2012).

Os constituintes do leite sofrem alterações pela dieta fornecida aos animais assim como também se modificam de acordo com os fatores climáticos, clima seco e úmido, do meio que estes vivem, influenciam no padrão desejável dos constituintes do leite.

A precipitação pluviométrica é o principal elemento meteorológico que determina as estações características (úmida e seca) do

\footnotetext{
*Recebido em 15 de outubro de 2013 e aceito em 29 de agosto de 2014.

**Universidade Federal do Rio Grande do Norte, Unidade Acadêmica Especializada em Ciências Agrárias, Departamento de Agropecuária, LABOLEITE,Macaíba, Rio Grande do Norte, Brasil.

***Universidade Federal Rural de Pernambuco, Departamento de Zootecnia, Recife, Pernambuco, Brasil.

${ }^{* * * *}$ Universidade Federal de Alagoas, Campus Arapiraca, Arapiraca, Alagoas, Brasil.
} 
Estado do Rio Grande do Norte. No Rio Grande do Norte, o índice pluviométrico médio anual, fica em torno de $823,6 \mathrm{~mm}$, apresentando uma variação nas diferentes regiões de modo que a maior média anual é observada na região Leste do Estado com 1246,3 mm, e a menor na região central $(630,4 \mathrm{~mm})$. Na região Agreste, esse índice é de $639,1 \mathrm{~mm}$, e na região Oeste (778,4 mm) (Bristot et al., 2012).

Diante do exposto, o presente trabalho teve como objetivo avaliar os indicadores da qualidade do leite cru de tanques de expansão em diferentes períodos do ano no estado do Rio Grande do Norte.

\section{Material e métodos}

Foram coletadas amostras de leite de oito rebanhos bovinos comerciais localizadas na região agreste do estado do Rio Grande do Norte, no período de janeiro de 2010 a março de 2012.

O procedimento de coleta era realizado após a homogeneização por meio de agitação mecânica, e posteriormente retiradas do tanque com o auxílio de uma concha de aço inoxidável devidamente higienizada. As amostras de leite foram acondicionadas em frascos plásticos de $40 \mathrm{~mL}$, contendo o conservante químico Bronopol $^{\circledR}$ (Microtabs) e para análises da contagem bacteriana total (CBT), foram adicionadas quatro gotas do conservante Azidiol, sendo posteriormente armazenadas em recipientes térmicos com gelo e encaminhadas para um laboratório integrante da Rede Brasileira de Laboratórios de Controle da Qualidade do Leite (Brasil, 2002) para fins de análises de composição através de Espectroscopia de Infravermelho com Transformada de Fourier (IVTF), utilizando-se o equipamento MilkoscanTM FT+ (Foss, Analytical). Para análise de contagem de células somáticas (CCS) usou-se a metodologia de contagem de células por meio do equipamento (Somacount 500 ) e para análise da contagem bacteriana total (CBT), usou-se a metodologia de citometria de fluxo por meio do equipamento Bactocount (Bentley ${ }^{\circledR}$ Instruments, 2004).

Para avaliação da condição climática das propriedades, os índices mensais médios de precipitação pluviométrica foram coletados do banco de dados do setor de meteorologia da Empresa de Pesquisa Agropecuária do Rio Grande do Norte (EMPARN).

Para avaliação do efeito da precipitação pluviométrica sobre as médias da composição, CCS e da CBT, o ano foi dividido em dois períodos: período chuvoso (que compreende os meses de março a agosto) e o período seco (que corresponde aos meses de setembro a fevereiro). Os dados coletados nesta pesquisa foram testados quanto a homogeneidade das variâncias e a normalidade dos dados. Esses testes demonstraram a necessidade de se realizar transformação matemática da variável CCS para que fosse possível alcançar a normalidade e homogeneidade das variâncias. Foi utilizado o logaritmo (LOG) de $(x+1)$ na base 10 , onde o " $x$ " corresponde ao valor medido da variável CCS. Os dados de CCS transformados foram chamados de Escore de Células Somáticas (ECS) e apresentavam distribuição normal e homogeneidade de variância. Os dados foram analisados por comparação de médias, aplicando-se o teste de Tukey com $5 \%$ de probabilidade para erro do tipo I, pelo procedimento GLM (SAS, 2003).

\section{Resultados e discussão}

Os parâmetros de composição do leite não foram influenciados $(P>0,05)$ pela estação do ano (Tabela 1$)$. O regime alimentar parece ser o fator preponderante na variação da composição do leite entre as estações do ano (Rangel et al., 2008; Fragan et al., 2010). Provavelmente, a suplementação alimentar recebida pelas vacas em lactação dos diferentes rebanhos avaliados pode explicar a ausência de variação na composição do leite dos tanques.

Tabela 1: Médias e desvios padrão dos teores de gordura, proteína, extrato seco total e extrato seco desengordurado do leite bovino nos períodos chuvoso e seco

\begin{tabular}{lcc}
\hline \multirow{2}{*}{ Componentes do leite } & \multicolumn{2}{c}{ Estação do ano } \\
\cline { 2 - 3 } & Seca & Chuvosa \\
\hline $\mathrm{N}^{*}$ & 83 & 96 \\
Gordura & $3,48 \pm 0,07^{\mathrm{a}}$ & $3,59 \pm 0,13^{\mathrm{a}}$ \\
Proteína & $3,29 \pm 0,05^{\mathrm{a}}$ & $3,31 \pm 0,05^{\mathrm{a}}$ \\
Extrato seco total & $12,13 \pm 0,18^{\mathrm{a}}$ & $12,25 \pm 0,05^{\mathrm{a}}$ \\
Extrato seco desengordurado & $8,65 \pm 0,11^{\mathrm{a}}$ & $8,66 \pm 0,08^{\mathrm{a}}$ \\
\hline
\end{tabular}

Médias seguidas de letras maiúsculas diferentes nas colunas diferem entre si pelo teste de Tukey $(\mathrm{P}<0,05)$

${ }^{*} \mathrm{~N}$ - número de observações

Buscando observar influencia das estações do ano sobre a composição do leite na região Sudeste do Brasil, Teixeira et al. (2003) e Roma Júnior et al. (2009) documentaram variação nos teores de gordura e proteína em rebanhos bovinos instalados nos estados Minas Gerais e São Paulo.

No Rio Grande do Sul, Noro et al.(2006) observaram que nos meses de verão, o teor de gordura $(3,41$ a $3,49 \%)$ foi menor que nos meses de inverno (em torno de $3,7 \%$ ) e o teor de proteína do leite foi afetado pelo mês de controle leiteiro, registrando-se teor de proteína maior nos meses de maio a setembro (em torno de $3,18 \%$ ) e menor teor nos meses de verão, sendo dezembro o mês com menor valor (3,02\%).

As médias para CCS e CBT também não sofreram efeitos do período seco e chuvoso (Tabela 2).

É recorrente na literatura elevações nos níveis de CCS e CBT no período chuvoso, principalmente pelo aumento das sujidades aderidas ao animal que dificultam a assepsia do úbere e podem colonizar tanto este órgão como o próprio leite (Fonseca e Santos, 2001). Assim, é provável que o manejo de ordenha higiênica, a ordenha mecânica e a higiene do recinto em que os animais se encontram favoreceram a ausência de diferença nos níveis de CCS e CBT entre as duas estações avaliadas.

A média da CCS no período chuvoso (610 mil células/ $\mathrm{mL}$ ) observada na tabela acima, não apresentou alteração significativa $(P<0,05)$ à média apresentada no período seco (557 mil células $/ \mathrm{mL}$ ). Diferentemente do estudo realizado por Martins et al. (2006) e Magalhães et al. (2006) em que a CCS se apresentou mais baixa no período seco e mais alta no chuvoso, como no verão ocorre aumento na umidade e maior estresse 
Tabela 2: Médias e desvios padrão da contagem de células somáticas (CCS) e contagem bacteriana total (CBT) do leite bovino de acordo com a precipitação pluviométrica (PP)

\begin{tabular}{lcccc}
\hline & \multicolumn{2}{c}{$\mathrm{N}$} & \multicolumn{2}{c}{ Período } \\
\cline { 2 - 5 } & Seco & Chuvoso & Seco & Chuvoso \\
\hline PP (mm) & 57 & 82 & $71^{\mathrm{b}}$ & $122^{\mathrm{a}}$ \\
CCS (mil cel./mL) & 83 & 96 & $557 \pm 300,62^{\mathrm{a}}$ & $610 \pm 184,12^{\mathrm{a}}$ \\
CBT (mil UFC $/ \mathrm{mL})$ & 68 & 82 & $795 \pm 76,27^{\mathrm{a}}$ & $505 \pm 31,15^{\mathrm{a}}$ \\
\hline
\end{tabular}

Médias seguidas de letras maiúsculas diferentes nas colunas diferem entre si pelo teste de Tukey $(P<0,05)$

${ }^{*} \mathrm{~N}$ - número de amostras analisadas

térmico, aumentam a susceptibilidade do animal a infecções e o número de patógenos aos quais estaria exposto, favorecendo a incidência de mastite nos períodos estudados.

Às observações realizadas por Harmon (1994) e Philpot (2002) relatam que a CCS pode aumentar nas épocas mais quentes do ano em decorrência da menor produção de leite e consequente concentração das células somáticas. Alia-se a isso a maior probabilidade de ocorrência de infecção intramamária, isoladamente, o principal fator responsável pela elevação da CCS. Para Zanela et al. (2006), a maior especialização dos

\section{Referências}

Bentley Instruments. Bactocount 150: operator's manual. Chaska, 2004, p. 35.

Borges K.A.; Reichert S.; Zanela M.B.; Fischer V. Avaliação da qualidade do leite de propriedades da região do Vale do Taquari no estado do Rio Grande do Sul. Acta Scientiae Veterinariae. v. 37, n. 1, p. 39-44, 2009.

Brasil. Ministério da Agricultura, Pecuária e Abastecimento. Departamento de Inspeção de Produtos de Origem Animal. Instrução Normativa $n^{\circ} 51$, de 18 de setembro de 2002. Coleta de leite cru refrigerado e seu transporte a granel. Diário Oficial da República Federativa do Brasil, Brasília, n. 172, p. 8-13, 20 de set. 2002. Seção I.

Brasil. Ministério da Agricultura, Pecuária e Abastecimento. Departamento de Inspeção de Produtos de Origem Animal. Instrução Normativa $n^{\circ} 62$, de 29 de dezembro de 2011. Coleta de leite cru refrigerado e seu transporte a granel. Diário Oficial da República Federativa do Brasil, Brasília, n. 172, p. 8-13, 29 de dez. 2011. Seção I.

Bristot, G.; Pinheiro, J. U.; Santos, M.F. As condições da pluviometria no estado do Rio Grande do Norte e as consequências da estiagem na produção de feijão neste estado. Disponível em: <http://www.cbmet.com>. Acesso em: 10 jun. 2012

Bueno, V.F.F.; Mesquita, A.J.; Oliveira, A.N.; Nicolau, E.S.; Neves, R.B.S. Contagem bacteriana total do leite: relação com a composição centesimal e período do ano no Estado de Goiás. Revista Brasileira de Ciência e Veterinária, v. 15, n. 1, p. 40-44, 2008. sistemas resulta em maior produção de leite por animal e devido a isso uma menor CCS. De acordo com Silva et al. (2010) a elevada CCS no tanque de expansão pode sinalizar perda de produção de leite, sendo que a baixa CCS no tanque de expansão é um indicativo de bom estado sanitário da glândula mamária.

Na Tabela 2, pode ser notado que a CBT não demonstrou mudança expressiva $(P<0,05)$ no período chuvoso quando comparado ao período seco. O presente trabalho difere das observações realizadas por Bueno et al. (2008) onde a CBT foi significativamente maior no período chuvoso. Segundo o autor o período das chuvas favorece o aumento da contaminação ambiental, o acúmulo de lama nas instalações e maior ocorrência de tetos sujos no momento da ordenha. Esses fatores, associados às falhas na rotina de ordenha, podem causar uma elevada contaminação inicial. Segundo Hogan et al. (1988) a CBT é influenciada pela elevada umidade e temperatura ambiente.

\section{Conclusão}

A estação do ano não influenciou na composição, contagem de células somáticas e contagem bacteriana total do leite cru de tanques de expansão no agreste do estado do Rio Grande do Norte.

Cassoli, L. D.; Machado, P. F. Manual de instruções para coleta e envio de amostras de leite para análise. Piracicaba: Clínica do Leite, ESALQ/USP, 2007.

Dürr, J.W. Programa nacional de melhoria da qualidade do leite: uma oportunidade única. In: Dürr, J. W.; Carvalho, M. P.; Santos, M. V. (Ed.). O compromisso com a qualidade do leite no Brasil. Passo Fundo: Editora Universidade de Passo Fundo, 2004. p. 38-55.

Fagan, E. P.; Jobim, C. C.; Calixto Júnior, M.; Silva; M. S.; Santos, G. T. Fatores ambientais e de manejo sobre a composição química do leite em granjas leiteiras do Estado do Paraná, Brasil. Acta Scientiarum. Animal Sciences, v. 32, n. 3, p. 309-316, 2010.

Fonseca, L.F.L. Pagamento por qualidade: situação atual e perspectivas para o setor lácteo brasileiro - parte 1. Disponível em: <http://www.milkpoint.com.br>. Acesso em: 19 maio. 2012.

Fonseca, L.F.L.; Santos, M.V. Qualidade do leite e controle da mastite. São Paulo: Lemos, 2001. 175 p.

Harmon, R.J. Physiology of mastitis and factors affecting somatic cell counts. Journal of Dairy Science, v. 77, n. 7, p. 2103-12, 1994.

Hogan, J.S.; Hoblet, K.H.; Smith, K.L.; Todhunter, D.A.; Schoenberger, P.S.; Hueston, W.D.; Pritchard, D.E.; Bowman, G.L.; Heider, L.E.; Brockett, B.L.; Conrad, H.R. Bacterial and somatic cell counts in bulk tank milk from nine well managed herds. Journal of Food Protection, v. 51, n. 12, p. 930-934, 1988.

Magalhães, H. R.; El Faro, L.; Cardoso, V. L.; Paz, C. C. P.; Cassoli, L. D.; Machado, P. F. Influência de fatores de ambiente sobre a contagem de células somáticas e sua relação com perdas na produção de leite de vacas da raça Holandesa. Revista Brasileira de Zootecnia, v. 35, n. 2, p. 415-421, 2006. 
Martins, P.R.G.; Silva, C.A.; Fischer, V.; Ribeiro, M. E. R.; Gomes, J. F.; Stumpf Jr, W.; Zanela, M. B. Produção e qualidade do leite na bacia de Pelotas-RS em diferentes meses do ano. Ciência Rural, v. 36, p. 209-214, 2006.

Noro, G.; González, F.H.D.; Campos, R.; Dürr, J.W. Fatores ambientais que afetam a produção e a composição do leite em rebanhos assistidos por cooperativas no Rio Grande do Sul. Revista Brasileira de Zootecnia, v. 35, n. 3, p. 1129-1135, 2006;

Philpot, N.W.; Nickerson, S.C. Vencendo a luta contra a mastite. Piracicaba : Westfalia Surge/Westfalia Landtechnik do Brasil, 2002. 192 p.

Rangel, A. H. N.; Braga, A. P.; Lima Júnior, D. M. ; Lima, R. N.; Araújo, C. G. F. Influência de Fatores de Meio Ambiente sobre o Intervalo Entre Partos de Rebanhos da Raça Jersey. Revista Verde, v. 3, n. 4, p. 42-45.

Roma Júnior, L.C.; Montoya, J.F.G.; Martins, T.T.; Cassoli, L.D.; Machado, P.F. Sazonalidade do teor de proteína e outros componentes do leite e sua relação com programa de pagamento por qualidade. Arquivo Brasileiro de Medicina Veterinária e Zootecnia, v. 61, Supl., p.1411-1418, 2009.
Silva, M.A.P.; Santos, P.A.; Silva, J.W.; Leão, K.M.; Oliveira A.N.; Nicolau, E.S. Variação da qualidade do leite cru refrigerado em função do período do ano e do tipo de ordenha. Revista do Instituto Adolfo Lutz. v. 69, n. 1, p. 112-118, 2010.

Teixeira, N.M.; Freitas, A.F.; Barra, R.B. Influência de fatores de meio ambiente na variação mensal da composição e contagem de células somáticas do leite em rebanhos no Estado de Minas Gerais. Arquivo Brasileiro de Medicina Veterinária e Zootecnia, v. 55, p. 491-499, 2003.

Zanela, M.B.; Fischer,V.; Ribeiro, M.E.R.; Stumpf Junior, W.; Zanela, C.; Marques, L.T. et al. Qualidade do leite em sistemas de produção na região Sul do Rio Grande do Sul. Pesquisa Agropecuária Brasileira, v. 41, n.1, p.153-159, 2006. 